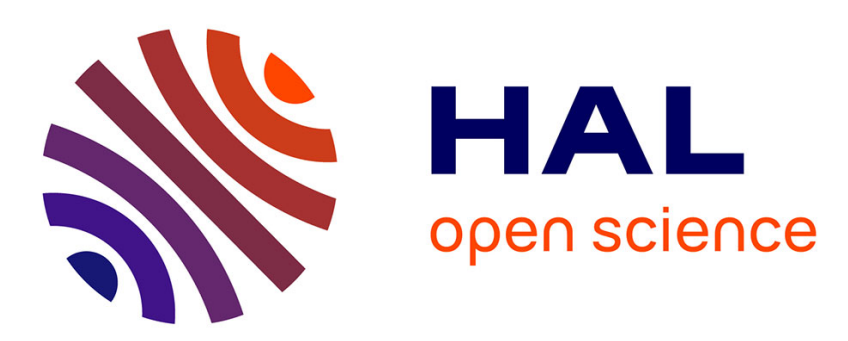

\title{
Forced assembly by multilayer coextrusion to create oriented graphene reinforced polymer nanocomposites
}

Xiguang Li, Guillaume Miquelard-Garnier, Alain Guinault, Cyrille Sollogoub, Gilles Regnier, Artur Rozanski

\section{- To cite this version:}

Xiguang Li, Guillaume Miquelard-Garnier, Alain Guinault, Cyrille Sollogoub, Gilles Regnier, et al.. Forced assembly by multilayer coextrusion to create oriented graphene reinforced polymer nanocomposites. Polymer, 2013, 55 (1), pp.248-257. 10.1016/j.polymer.2013.11.025 . hal-00980636

\section{HAL Id: hal-00980636 https://hal.science/hal-00980636}

Submitted on 13 May 2014

HAL is a multi-disciplinary open access archive for the deposit and dissemination of scientific research documents, whether they are published or not. The documents may come from teaching and research institutions in France or abroad, or from public or private research centers.
L'archive ouverte pluridisciplinaire HAL, est destinée au dépôt et à la diffusion de documents scientifiques de niveau recherche, publiés ou non, émanant des établissements d'enseignement et de recherche français ou étrangers, des laboratoires publics ou privés. 


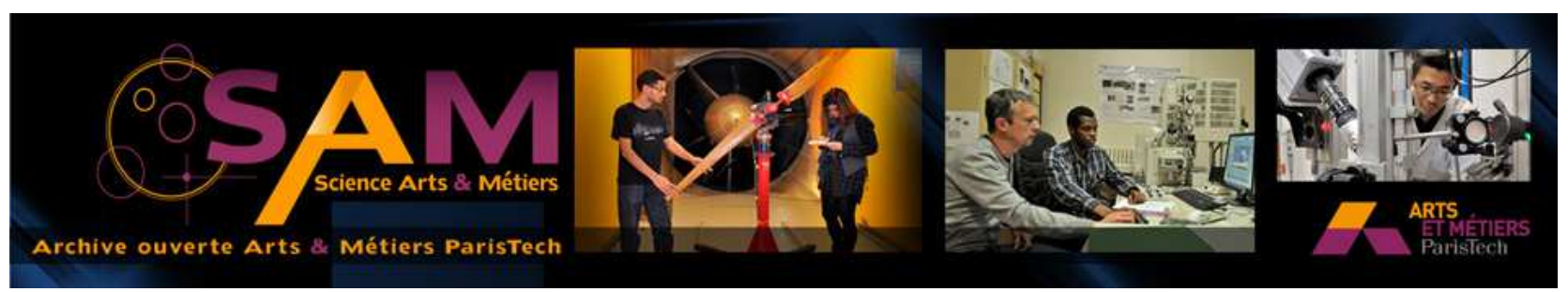

Science Arts \& Métiers (SAM)

is an open access repository that collects the work of Arts et Métiers ParisTech researchers and makes it freely available over the web where possible.

This is an author-deposited version published in: http://sam.ensam.eu Handle ID: .http://hdl.handle.net/10985/7987

\section{To cite this version :}

Xiguang LI, Gregory MCKENNA, Guillaume MIQUELARD-GARNIER, Alain GUINAULT, Cyrille SOLLOGOUB, Gilles REGNIER - Forced assembly by multilayer coextrusion to create oriented graphene reinforced polymer nanocomposites - Polymer - Vol. 55, n¹, p.248-257 - 2013 


\title{
Forced assembly by multilayer coextrusion to create oriented graphene reinforced polymer nanocomposites
}

\author{
Xiguang Li ${ }^{\mathrm{a}, \mathrm{b}}$, Gregory B. McKenna ${ }^{\mathrm{a}, *}$, Guillaume Miquelard-Garnier ${ }^{\mathrm{b}, *}$, Alain Guinault ${ }^{\mathrm{b}}$, \\ Cyrille Sollogoub $^{\mathrm{b}}$, Gilles Regnier ${ }^{\mathrm{b}}$, Artur Rozanski ${ }^{\mathrm{c}}$ \\ a Department of Chemical Engineering, Whitacre College of Engineering, Texas Tech University, Lubbock, TX 79409-4121, United States \\ b PIMM, Arts et Métiers ParisTech/CNRS/CNAM, 151 boulevard de l'Hôpital, 75013 Paris, France \\ ${ }^{\mathrm{C}}$ Centre of Molecular and Macromolecular Studies, Polish Academy of Sciences, 90-363 Lodz, Poland
}

Keywords:

Graphene

Nanocomposite

Forced assembly

\begin{abstract}
A B S T R A C T
A potential advantage of platelet-like nanofillers as nanocomposite reinforcements is the possibility of achieving two-dimensional stiffening through planar orientation of the platelets. The ability to achieve improved properties through in-plane orientation of the platelets is a challenge and, here, we present the first results of using forced assembly to orient graphene nanoplatelets in poly(methyl methacrylate)/ polystyrene (PMMA/PS) and PMMA/PMMA multilayer films produced through multilayer coextrusion. The films exhibited a multilayer structure made of alternating layers of polymer and polymer containing graphene as evidenced by electron microscopy. Significant single layer reinforcement of $118 \%$ at a concentration of 2 wt \% graphene was achieved-higher than previously reported reinforcement for randomly dispersed graphene. The large reinforcement is attributed to the planar orientation of the graphene in the individual polymer layers. Anisotropy of the stiffening was also observed and attributed to imperfect planar orientation of the graphene lateral to the extrusion flow.
\end{abstract}

\section{Introduction}

Single and multi-layer forms of graphite, graphene, graphene oxide and graphene nanoplatelets have attracted significant research interest in recent years [1,2]. Because of its outstanding mechanical properties, high surface area, extraordinary electrical and thermal conductivities, graphene has been reported to have a variety of potential applications, such as nanocomposites [3,4] energy storage [5], and photonic devices [6]. However, to date, most work on graphene polymer nanocomposites has focused on isotropic or random dispersion of the graphene in the polymer matrix, giving limited reinforcement [7]. If platelet-like fillers can be aligned in a plane of the polymer matrix, they provide the possibility of two-dimensional reinforcement in the plane of orientation [8]. Theoretically, if the requirements of both high volume fraction of filler and in-plane alignment of the platelets are met, the mimicking of nacre-like [9] structures might be achieved. Therefore, methods to create such structures, especially with a potentially industrially useful method, are desirable and important.

\footnotetext{
* Corresponding authors.

E-mail addresses: greg.mckenna@ttu.edu (G.B. McKenna), guillaume.miquelard_ garnier@cnam.fr (G. Miquelard-Garnier).
}

In the general case, graphene nanocomposites have been made in ways that emphasize good dispersion and have not examined heavily the possibility of creating oriented structures. For example, it has been reported $[3,4]$ that dispersing graphene or graphene oxide into a polymer matrix at low loadings ( $<1 \mathrm{wt} \%$ ) can lead to good mechanical reinforcement for polymer nanocomposites, such as PMMA/graphene oxide [3] (33\% enhancement of Young's modulus at only $0.01 \mathrm{wt} \%$ ). One reason that has been given for the apparent strong reinforcement is that, via a solution mixing method, graphene and graphene oxide are dispersed with a wrinkled topology in the host polymer matrix [3]. Some researchers think that this provides strong interfacial adhesion between graphene and the polymer chains with a consequent significant increase in the glass transition temperature $\left(T_{\mathrm{g}}\right)$ of the polymer matrix $[3,4]$. If this is the case, much of the high degree of reinforcement might be attributed to the changing thermoviscoelasticity of the polymer matrix due to the changing $T_{\mathrm{g}}[10]$ rather than to a mechanical reinforcement per se. In addition to bench scale solution mixing, graphene nanoplatelets can also be dispersed into a polymer matrix via melt mixing, e.g. in most cases through extrusion, which is the most relevant tool for exploring potential industrial applications [7,11-14]. However, due to the high viscosities of polymer melts, melt extrusion usually falls short of providing effective dispersion of nanofillers and results in filler 
aggregation $[12,14]$. Recently it has been shown that this method can be improved by multiplying the number of extrusion steps: a concentrated solid mixture of filler in polymers (or "master batch") is produced by melt mixing then further dilution one or more times with the same polymer to the desired concentration $[15,16]$. It has been found that this technique can result in better dispersion of the nanofiller with consequently better composite mechanical properties. One reported example is the improved dispersion of graphene into a polyetherimide by Bian et al. [14].

To the best of our knowledge, the development of methods to create in-plane oriented graphene in a polymer matrix in order to realize two-dimensional reinforcement have not been undertaken either for bench scale solution mixing or for melt extrusion. Kim and Macosko reported the production of slightly oriented polycarbonate/graphene nanocomposites obtained from injection molding. However, they also reported that wrinkling of the graphene in the polymer matrix resulted in only weak reinforcement [13]. Bian et al. reported dispersion and alignment of graphene in polypropylene by injection molding, but the mechanical reinforcement in that case could be attributed to increased crystallinity due to the graphene acting as a nucleating agent [14].

Multilayer coextrusion is an attractive technique to produce up to thousands of alternating layers in films with individual layer thicknesses from $10 \mathrm{~nm}$ to multiple $\mu \mathrm{m}[17,18]$. In pioneering work, Baer and coworkers have used this "forced assembly" technique and have shown that immiscible polymer pairs and filled/unfilled polymers can be forced to combine into a unique multilayer structure, accompanied with interesting confined crystallization effects [19], gas barrier properties [20], and optical properties [21]. In addition, Koets et al. report the toughening of immiscible amorphous polymer pairs by multilayer coextrusion [22].

Since multilayer coextrusion is scalable to industrial processing and alignment of anisotropic nanofillers can make desirable composites, it offers an attractive approach to orient nanoparticles with high aspect ratio $A_{\mathrm{f}}$, such as graphene nanoplatelets, in the layer plane. What we search to achieve in the present study is evidence that the forced assembly, by creating a structure with extremely thin layers filled with graphene, has the potential of creating a new type of nanocomposite in which in-plane oriented graphene is the reinforcing element. Fig. 1 shows a schematic of the multilayer coextrusion method of forced assembly and how the geometric constraints and the complex flow that includes biaxial stretching [23] may create the oriented graphene layers in the multilayer film.

To date the idea of dispersing and orienting anisotropic nanofillers through multilayer coextrusion has been only briefly investigated. In 1999, the Baer group reported incorporating talc micro-platelets into poly(ethylene terephthalate) micro-layer films to reduce oxygen permeability [23]. Very recently, Guo et al. [24] reported that enhanced electrical conductivity can result from oriented carbon nanotubes in layers with carbon black in polypropylene films formed through multilayer coextrusion. And Miquelard-Garnier et al. [25] have also reported on nanocomposites with improved mechanical properties through the dispersion of carbon nanotubes in polypropylene via multilayer coextrusion. However, to the best of our knowledge, multilayer coextrusion has not been exploited to orient platelet-like nanofillers, such as graphene, to reinforce polymer matrixes, with particular thought to creating a biaxially reinforced medium.

In the present study, we use forced assembly by multilayer coextrusion to develop a new class of polymer nanocomposites with planar oriented graphene nanoplatelets to achieve twodimensional reinforcement. To this end we prepared and studied two different nanocomposites made using the amorphous polymers polystyrene (PS) and poly(methyl methacrylate) (PMMA). The PMMA/PS couple is a typical alternating layered film structure used in multilayer coextrusion studies [22,26]. Furthermore, commercial polystyrene/graphene master batch materials are now available in reasonable quantities. Therefore, the immiscible PMMA/graphene filled PS (PMMA/PS-graphene) system was the first that we investigated. In this instance we used a commercial PS/graphene master batch and compared the films obtained with similar films using a lab-made PS/graphene master batch. As poor strength of the films was observed, possibly due to the poor bonding between graphene and PS, and the weak interface between the PS and PMMA layers, we also made our own master batch of PMMA/graphene and used this to investigate the properties of PMMA/PMMA-graphene nanocomposites.

The morphology of the continuous layers and orientation of the graphene nanoplatelets were characterized with electron microscopy. Quasi-static mechanical and dynamic mechanical properties of the materials were determined. Differential scanning calorimetry was used to determine the glass transition temperatures of the systems, hence permitting us to evaluate the magnitude of any apparent reinforcement due to the changing viscoelasticity of the matrix materials due to a change in $T_{\mathrm{g}}[10]$.

\section{Experimental methods}

\subsection{Materials}

Neat poly(methyl methacrylate) was supplied by Altuglas International (PMMA V920T, MFI is $6 \mathrm{~g} / 10 \mathrm{~min}$ at $230^{\circ} \mathrm{C} / 3.8 \mathrm{~kg}$; GPC using tetrahydrofuran and calibrated with polystyrene standards gives $\mathrm{Mw}=110 \mathrm{k}, \mathrm{PDI}=2.15$ ) and neat polystyrene was obtained from Total Petrochemicals (PS 1340, MFI is $4 \mathrm{~g} / 10 \mathrm{~min}$ at $200^{\circ} \mathrm{C} / 5 \mathrm{~kg}$; GPC in THF gives $\mathrm{Mw}=286 \mathrm{k}, \mathrm{PDI}=1.66$ ). The graphene nanoplatelets came from two sources: virgin graphene nanoplatelets obtained from ACS Materials were used to make PS/graphene and

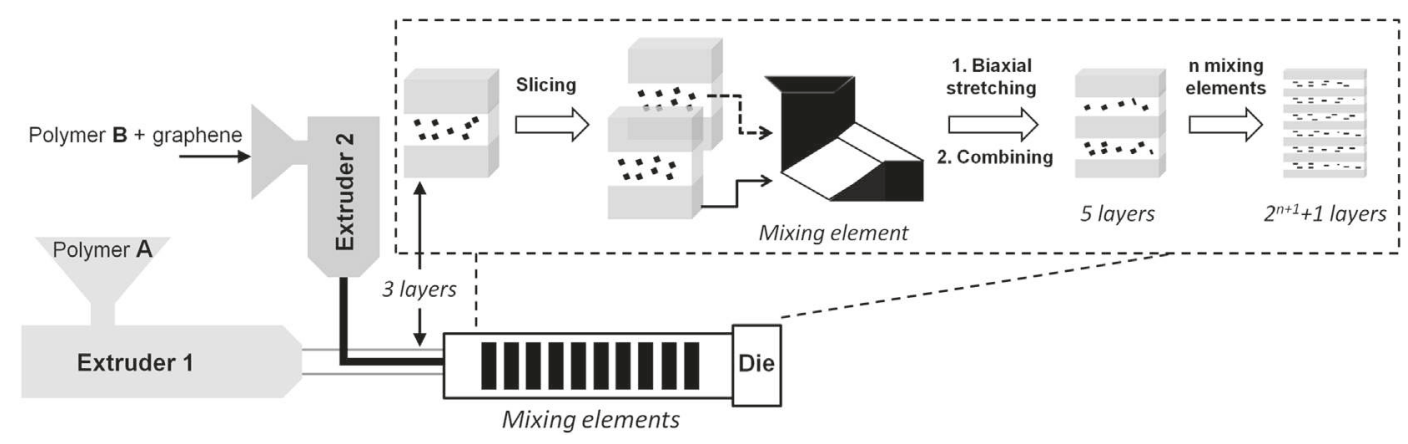

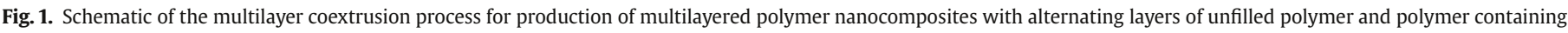
oriented graphene. 
PMMA/graphene master batches in our laboratories. Prior to extrusion the PMMA systems were dried in a SOMOS dry air dryer T 20 eco system at $80{ }^{\circ} \mathrm{C}$ for $4 \mathrm{~h}$. A commercial polystyrene/15\% graphene nanoplatelet filled master batch was obtained from Ovation Polymers Company. The characteristics of the master batches and the graphene nanoplatelets are presented in Table 1.

\subsection{Preparation of lab made polymer/graphene master batches}

The lab-made PMMA/20 wt \% graphene master batch was prepared from the Altuglas PMMA and the ACS Materials graphene nanoplatelets following a solution mixing method used by Ramanathan et al. [3] and adapted here for bigger quantities. 15 g graphene and $60 \mathrm{~g}$ PMMA were dissolved in $600 \mathrm{mLTHF}$ (Emparta ACS) at $40{ }^{\circ} \mathrm{C}$ and the mixture was mechanically stirred for $2 \mathrm{~h}$ to assure good dispersion. The mixture was precipitated by adding $6 \mathrm{~L}$ water and vacuum dried at $80{ }^{\circ} \mathrm{C}$ for $24 \mathrm{~h}$. The lab-made PS/graphene master batch (20 wt \%) was prepared using the same method.

\subsection{Preparation of the polymer/graphene formulations}

Prior to multilayer coextrusion, the relevant PMMA-graphene formulations $(0.5,1.0$ and $2.0 \mathrm{wt} \%)$ to be used in extruder 2 (see Fig. 1) were prepared by diluting the PMMA-20 wt \% graphene with the neat PMMA using a Thermo Haake PTW 16-40D co-rotating twin-screw extruder at $600 \mathrm{rpm}$ and $215{ }^{\circ} \mathrm{C}$. The PS-graphene formulations $(0.5,2.0$ and $4.0 \mathrm{wt} \%)$ were prepared by diluting the commercial PS/15 wt \% graphene master batch from Ovation Polymers Company with the Total Petrochemicals PS, using the same twin-screw extruder at $200{ }^{\circ} \mathrm{C}$ with co-rotating mixing, again, at $600 \mathrm{rpm}$. The specific mechanical energy $(\mathrm{SME}=$ torque $\times$ screw speed of the extruder/throughput of the mixing) was around $5000 \mathrm{~kJ} / \mathrm{kg}$ for the PMMA systems and $8000 \mathrm{~kJ} / \mathrm{kg}$ for the PS systems. For the two systems, this value was fixed as high as possible, following studies by Pötschke [27] and others [25] showing that a high SME value for twin-screw extrusion results in better dispersion of nanofillers in polymers.

Multilayer coextrusion requires a reasonable viscosity match between the polymer melt streams [18]. In the present study, because the films were prepared with different amounts of graphene nanoplatelets, the viscosity ratio between the two melt streams ( $\left.\eta_{\text {graphene filled polymer }} / \eta_{\text {PMMA }}\right)$ could not be maintained constant. The viscosity ratios were obtained from the apparent steady shear viscosities of all polymers and graphene formulations as a function of temperature to choose acceptable operating conditions. The viscosity ratio varied with increasing concentration of graphene. At the shear rate of $4 \mathrm{~s}^{-1}$ to simulate the flow condition in the extrusion, for the PMMA/PS-graphene systems $(0.5,2$ and $4 \mathrm{wt} \%$ ) the variation of viscosity ratio was from 0.25 to 0.53 at

Table 1

Material characteristics reported by manufacturers.

\begin{tabular}{|c|c|c|c|c|c|}
\hline Master batch & $\begin{array}{l}\text { Graphene } \\
\text { concentration }\end{array}$ & $\begin{array}{l}\text { Graphene } \\
\text { source }\end{array}$ & $\begin{array}{l}\text { Graphene } \\
\text { thickness } \\
\text { /nm }\end{array}$ & $\begin{array}{l}\text { Graphene } \\
\text { size/ } / \mu \mathrm{m}\end{array}$ & $\begin{array}{l}\text { Graphene } \\
\text { aspect } \\
\text { ratio } A_{\mathrm{f}}\end{array}$ \\
\hline $\begin{array}{l}\text { Lab made } \\
\text { PMMA } \\
\text { /Graphene }\end{array}$ & 20 wt $\%$ & $\begin{array}{l}\text { ACS } \\
\text { materials } \\
\text { GnP }\end{array}$ & $2-10$ & $5-10$ & $1000-2000$ \\
\hline $\begin{array}{l}\text { Lab made PS } \\
\text { /Graphene }\end{array}$ & 20 wt $\%$ & $\begin{array}{l}\text { ACS } \\
\text { materials } \\
\text { GnP }\end{array}$ & $2-10$ & $5-10$ & $1000-2000$ \\
\hline $\begin{array}{l}\text { PS/Graphene } \\
\text { from ovation } \\
\text { polymers }\end{array}$ & 15 wt $\%$ & X-GnP M15 & 5 & 15 & 3000 \\
\hline
\end{tabular}

$240{ }^{\circ} \mathrm{C}$ and for the PMMA/PMMA-graphene systems (0.5, 1 and $2 \mathrm{wt}$ $\%)$ it varied from 1 to 0.53 at $225^{\circ} \mathrm{C}$.

\subsection{Fabrication of multilayer polymer/polymer-graphene films}

Using a multilayer coextrusion process (Fig. 1), the primary polymer melt A (in this study always PMMA) and the secondary polymer melt B (PMMA or PS) filled with graphene, were extruded from two single-screw extruders (Extruder 1: Mapre, $30 \mathrm{~mm}$ diameter with a barrel of length-to-diameter ratio of 33 and speed fixed at $37 \mathrm{rpm}$; Extruder 2: Scamex, $20 \mathrm{~mm}$ diameter with a barrel of length-to-diameter ratio of 20 and speed between 30 and $45 \mathrm{rpm}$ ) respectively, combined in a classical three layer coextrusion feed block (ABA). In this study, the percentage of polymer B in the film was kept constant at $10 \mathrm{wt} \%$. Exact values for this ratio were calculated after extrusion by measuring the mass flow rate and always found to be between 9.3 and $10.8 \%$.

The three-layer melt block flows through a series of mixing elements with the process of vertical slicing, biaxial stretching and recombining $[24,25]$ shown in Fig. 1 to produce $2^{\mathrm{n}+1}+1$ layers (n being the number of mixing elements). In this study, 0,6 and 10 mixing elements were used, giving films containing respectively 3 , 129 and 2049 layers. These are then spread through a flat die (width $=100 \mathrm{~mm}$, thickness $=1 \mathrm{~mm}$ ) and onto a chill roll drawn at $1.7 \mathrm{~m} / \mathrm{min}$ and maintained at $80{ }^{\circ} \mathrm{C}$ to allow relaxation of the PMMA. The result is a rectangular film made up of the alternating layers. For the two single-screw extruders, mixing elements and die were set to $225^{\circ} \mathrm{C}$ for the PMMA/PMMA systems and $240^{\circ} \mathrm{C}$ for the PMMA/PS systems. The residence time for the melts in the mixing element segment, estimated using the throughput of the extruder is approximately $2 \mathrm{~min}$.

The final concentration of graphene was then $0.05,0.1$ and $0.2 \mathrm{wt} \%$ in the PMMA/PMMA films, and $0.05,0.2$ and $0.4 \mathrm{wt} \%$ in the PMMA/PS films if both filled and unfilled layers are counted.

\subsection{Morphological analysis}

Optical microscopy: $20 \mu \mathrm{m}$ thick slices were obtained using a Leica RM 2225 microtome. The cuts were made perpendicular to the extrusion flow direction. They were then observed by transmission optical microscopy using an Olympus BH2-UMA. Images were analyzed using Image (an open source image processing software developed by the National Institutes of Health) and at least five images were used for quantitative analysis.

Electron microscopy:

- Scanning electron microscopy (SEM) and scanning transmission electron microscopy (STEM): $70-80 \mathrm{~nm}$ thick slices from the films were obtained using a LKB BROMMA 2088 ultratome with a glass knife at the speed of $2 \mathrm{~mm} / \mathrm{s}$. The cuts were perpendicular to the extrusion flow direction. Images were collected using a HITACHI 4800 SEM in SEM and STEM modes.

- Transmission electron microscopy (TEM): TEM was performed using a TESLA BS500 electron microscope operating at $90 \mathrm{kV}$. Approximately $50 \mathrm{~nm}$ thick sections were microtomed from multilayered films with a Power Tome XL ultramicrotome equipped with a diamond knife. Again, cuts were perpendicular to the extrusion direction.

\subsection{Property measurements}

\subsubsection{Steady shear viscosity measurement}

The apparent steady shear viscosity of all polymers and graphene formulations were determined using an ARES Rheometer 
(TA Instruments) with $25 \mathrm{~mm}$ diameter parallel plate fixture at a shear rate of $4 \mathrm{~s}^{-1}$ to simulate the flow condition in the extrusion. In the mixing elements section, one can estimate the shear flow knowing the throughput of the extruder (around $6 \mathrm{~kg} / \mathrm{h}$ ), the density of the PMMA (1.18) and the dimensions of the mixing elements $(10 \times 10 \mathrm{~mm})$ and obtain a value close to $8 \mathrm{~s}^{-1}$. The $4 \mathrm{~s}^{-1}$ shear rate was chosen because the high viscosity system gave a torque at the limit of the instrument for this rate.

\subsubsection{Mechanical properties}

Quasi-static mechanical properties of the multilayer films were determined in uniaxial extension using an Instron 4301 testing machine with a $1 \mathrm{kN}$ load cell. At least five specimens of each sample $\left(0.3-0.5 \times 10 \times 110 \mathrm{~mm}^{3}\right)$, cut parallel and transverse to the extrusion flow direction, were tested at ambient temperature and $50 \%$ relative humidity at a cross head speed of $5 \mathrm{~mm} / \mathrm{min}$. Strain was obtained from the cross head displacement and original sample length $(110 \mathrm{~mm})$ between the grips of testing machine. Tensile modulus was calculated within the linear regime of strain $(0.2-$ $0.4 \%$ ) from the stress versus strain curves.

The dynamic moduli at a single frequency of $1.0 \mathrm{~Hz}$ were determined using a TA Instruments Q800 DMA with a rectangular specimen $\left(0.3-0.5 \times 5 \times 20 \mathrm{~mm}^{3}\right)$. Compliance was calibrated with a stainless steel strip by using the internal instrument procedure. A dynamic temperature ramp at $2{ }^{\circ} \mathrm{C} / \mathrm{min}$ was run at $1 \mathrm{~Hz}$ and $0.5 \%$ strain over the temperature range from $40{ }^{\circ} \mathrm{C}$ to $130{ }^{\circ} \mathrm{C}$. It was verified that the measurement remained in the linear viscoelastic domain. Three samples were tested for each type of sample investigated.

\subsubsection{Glass transition temperature determination}

The glass transition temperature $T_{\mathrm{g}}$ was determined from calorimetry as the limiting fictive temperature $T_{\mathrm{f}}{ }^{\prime}[28,29]$. The calorimeter was a TA Q10 differential scanning calorimeter (DSC, TA Instruments) and the tests were run in heating at $10{ }^{\circ} \mathrm{C} / \mathrm{min}$ after cooling at $10^{\circ} \mathrm{C} / \mathrm{min}$ from a temperature of $130{ }^{\circ} \mathrm{C}$ under nitrogen flow.

\subsubsection{Annealing test}

Films were cut to $5 \times 5 \mathrm{~mm}^{2}$ and annealed at $125{ }^{\circ} \mathrm{C}$ for $1 \mathrm{~h}$. The dimension change was obtained using optical microscopy to characterize de-orientation of the polymer chains.

\section{Results and discussion}

\subsection{Structure and morphology}

Electron microscopy was used to confirm the existence of the continuous layer structure of the films. Multilayer coextrusion produces polymer films with alternating layers, and the thickness of the layers is controlled by varying the number of layers and keeping the total thickness of the films constant. The overall thicknesses of the films in the present study were approximately $0.5 \mathrm{~mm}$ and $0.3 \mathrm{~mm}$ for PMMA/PS and PMMA/PMMA systems, respectively. For example, taking into account the weight ratio of 9:1 for the two polymer layers, the multilayer films with 2049 layers contained individual layers with a theoretical thickness of $500 \mathrm{~nm}$ for the PMMA and $65 \mathrm{~nm}$ for the PS in the PMMA/PSgraphene films, and $290 \mathrm{~nm}$ and $35 \mathrm{~nm}$ for PMMA/PMMAgraphene films. The layers then provide the geometric constraints to orient the graphene nanoplatelets.

Due to these constraints, graphene nanoplatelets were expected to be oriented in the confinement by the thin layers. The layer and orientation were studied by SEM, STEM and TEM. It was found that the concentration of graphene influenced the alternating layer structure.

\subsubsection{PMMA/PS-graphene system}

The STEM and SEM images of Fig. 2 show cross sections of the 2049-layer PMMA/PS films with 0 wt \%, 0.5 wt \%, 2 wt \% and 4 wt \% graphene nanoplatelets in the thin PS layers. The layer continuity was evidenced and the influence of graphene on the layer structure was studied, although the graphene confined in the thin PS layers was difficult to observe.

The PMMA and PS layers (white and black) are readily distinguished as continuous layers (Fig. 2a), with the thickness close to expectation (PS: 60-90 nm; PMMA: 300-600 nm), although with some nonuniformity with the addition of $0.5 \mathrm{wt} \%$ graphene (Fig. 2b). However, when the concentration of graphene is $2 \mathrm{wt} \%$ in the PS layers, some layers break and are no longer continuous. (Fig. 2c). We also note that the addition of graphene swells the layer, which may lead to the break-up of layers at higher concentrations of graphene. When there is $4 \mathrm{wt} \%$ graphene in the PS layers, most of the layers are broken, with some aligned lamellae and some droplets. (Fig. 2d) Therefore, $2 \mathrm{wt} \%$ graphene is found to be the upper limit in our filled layer to maintain the layer structure.

\subsubsection{PMMA/PMMA-graphene system}

We first used optical microscopy to characterize the morphology of the multilayer films at the micro-scale and to compare the dispersion of graphene nanoplatelets for films with different number of layers. To quantify the dispersion of graphene nanoplatelets, the fraction $R$ of the total aggregates with diameter $>5 \mu \mathrm{m}$ (area $>19.6 \mu \mathrm{m}^{2}$ ) over the total area of the sample was determined following the work of Pötschke [27]. Although the value obtained cannot be related to the real volume fraction of aggregates in the sample, concerning the thickness of the sample imaged, it is still observed that the large aggregation (particles $>5 \mu \mathrm{m}$ in diameter) fraction $R$ decreases as the number of layers increases. Although it is clear that some large aggregates remain in the sample, which certainly results in the local perturbation of the nano-scaled layers even when 10 mixing elements are used, the dispersion of the graphene nanoplatelets and the breakage of aggregates in the relevant polymer matrix appears to increase upon increasing the number of layers. In the process of multi-layer co-extrusion, the mixing elements slice the melts with the result that the graphene aggregates are broken up to a large extent. In addition, due to the limitation of resolution, optical microscopy is not able to show the layers below $1 \mu \mathrm{m}$ (For the PMMA/ PMMA films, the thickness of the filled layers are $450 \mathrm{~nm}$ and $35 \mathrm{~nm}$ for the 129 and 2049 layer films, respectively). In addition, the contrast between PMMA layers is too low to show distinct layers using optical microscopy. These are the reasons that Fig. 3 does not show a distinct layered structure.

STEM and TEM were in consequence used to study the graphene orientation and aspect ratio, when the layer thickness reaches the nano-scale in the 2049-layer films (see Fig. 4). With no graphene, as expected (Fig. 4a), there is no clear distinction between the thin PMMA and the thick PMMA layers. However, when there is $1 \mathrm{wt} \%$ graphene in the thin PMMA layers, the individual graphene nanoplatelets can be observed and appear mostly oriented in the plane of the layers (horizontal direction in Fig. 4b), with distribution of platelet length ranging from approximately 50-150 nm.

When there is $2 \mathrm{wt} \%$ graphene in the layers, the concentration appears to reach, similar to the PMMA/PS system, an upper limit which starts to perturb the nanostructure (Fig. $4 \mathrm{c}$ and d). Fig. 4c displays some small or wrinkled graphene nanoplatelets which are still expected to be confined within the thin layers (dashed 


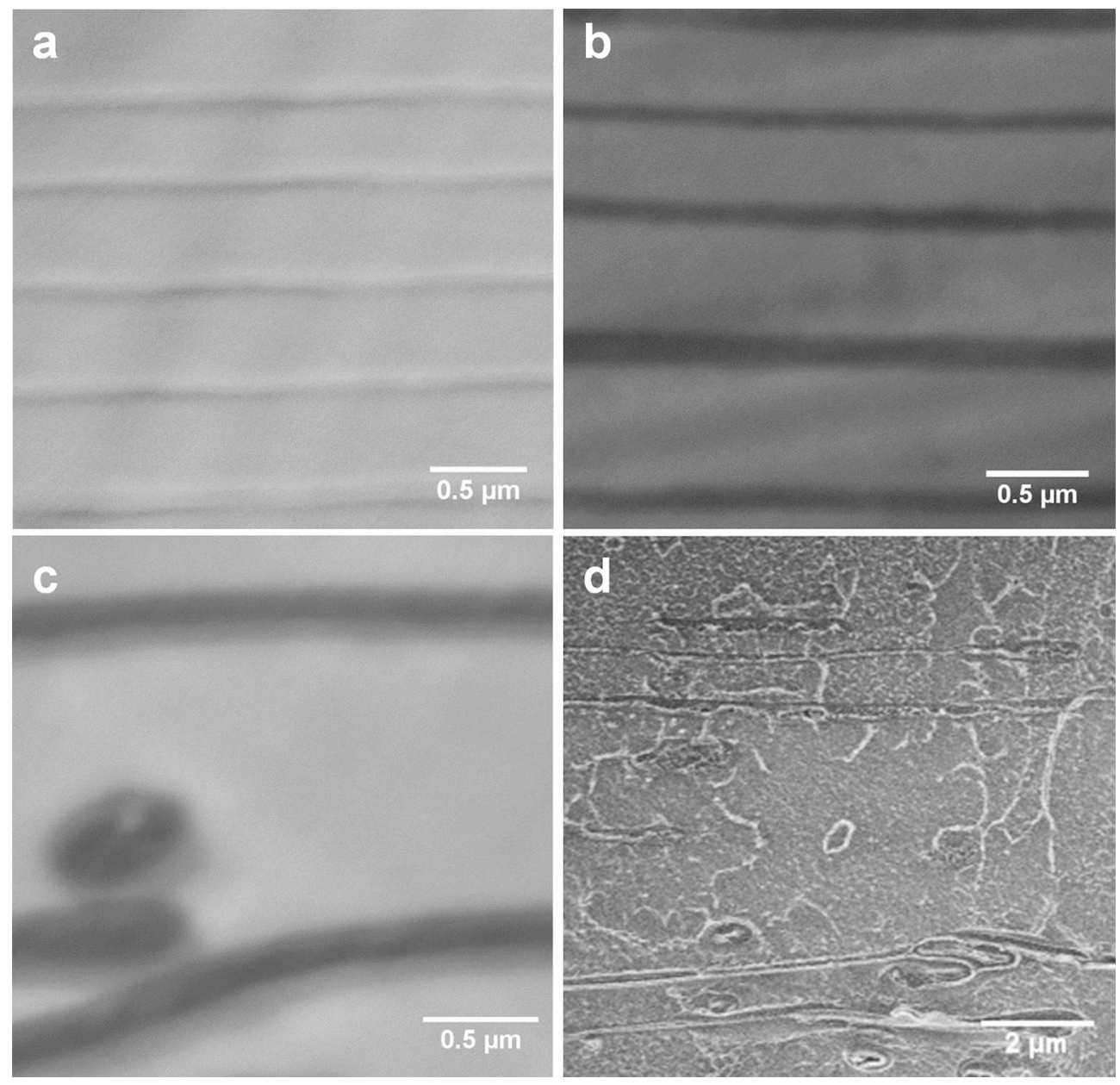

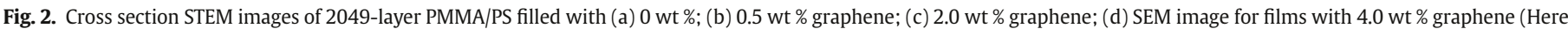

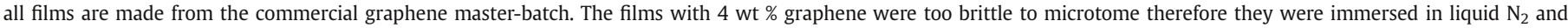
cryogenically fractured before imaging by SEM).

lines), similar to the results reported by Gupta et al. [20] for polypropylene/10 vol. \% phosphate glass particle filled polypropylene multilayer films. On the other hand, Fig. 4d shows a large and oriented graphene with a length of approximately $600 \mathrm{~nm}$. Although there are some stacks of graphene nanoplatelets, e.g. 60 layers of graphene with $20 \mathrm{~nm}$ thickness, the stacks of graphene can still be confined in the thin layers (30-40 nm thick). It is also possible that the thick-looking graphene nanoplatelets are not stacks of graphene, but rather they are titled platelets.

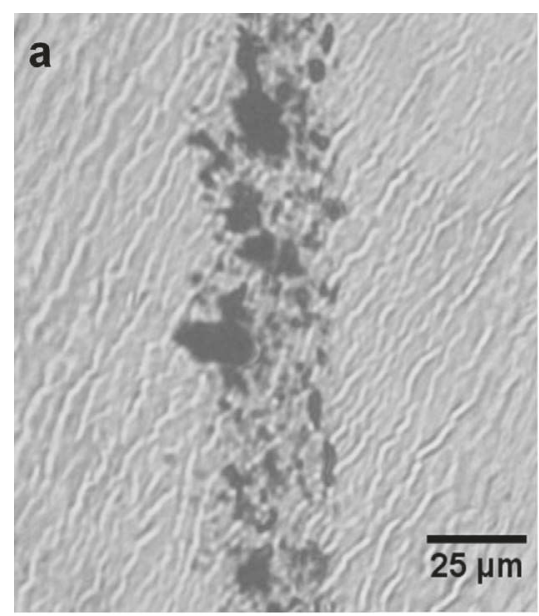

$R(\%)=3.6 \pm 1.0$

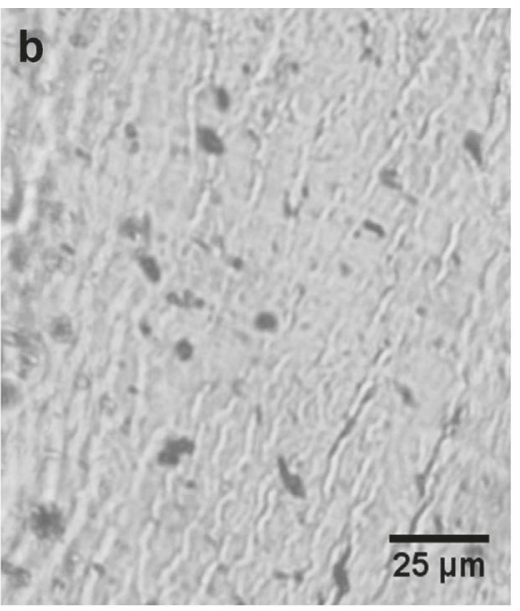

$R(\%)=1.5 \pm 0.28$

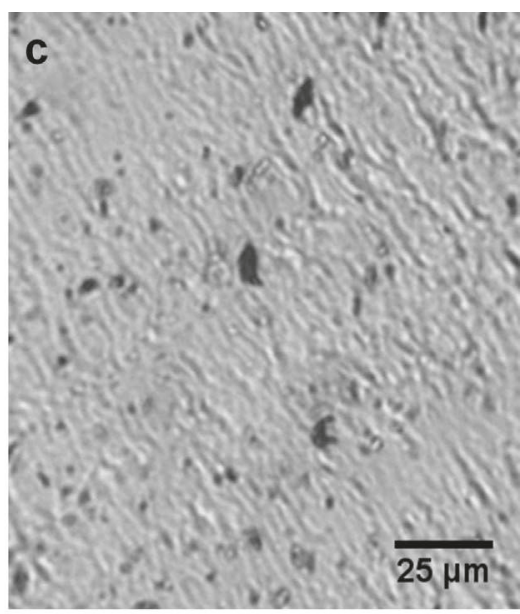

$R(\%)=0.5 \pm 0.15$

Fig. 3. Optical images of PMMA/PMMA filled with $1 \mathrm{wt} \%$ graphene. (a: 3-layer, b: 129-layer and c: 2049-layer) and large aggregations fraction $R$. 


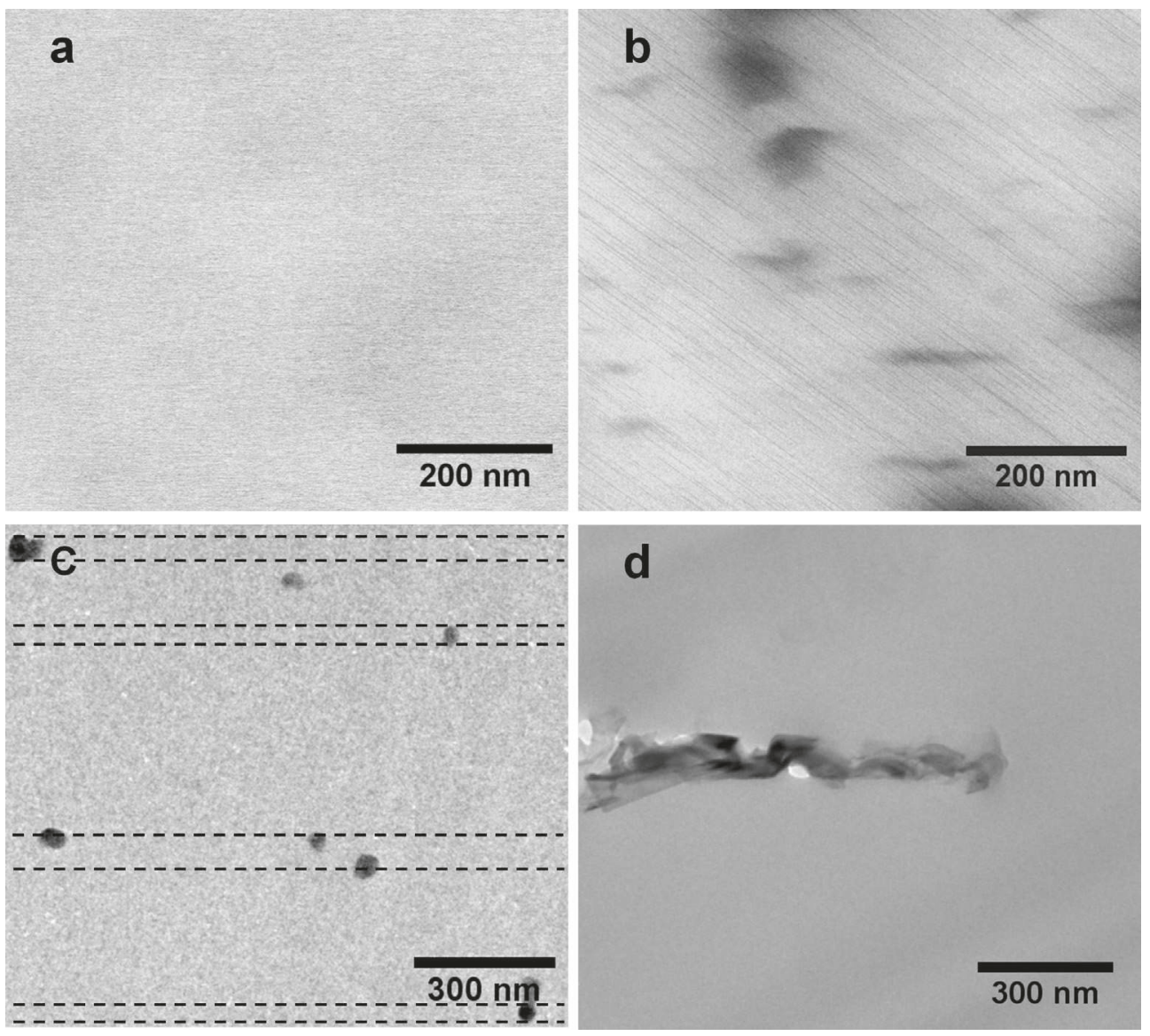

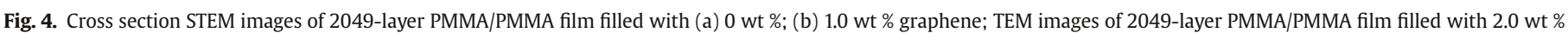
graphene (c) showing graphene confinement (dashed lines represent the tentative positions of the thin PMMA layers) (d) showing a single aligned graphene particle.

It should be noted that the length of the graphene nanoplatelets is, in any case, smaller than the data provided by the suppliers, but the observed particles may not be totally flat (since thickness, on the contrary appears greater than the supplier provided information (see Table 1). Extrusion is also known to result in the shortening and breakage of nanofibers [27] and nanoplatelets [30], so this is not unexpected.

As seen in Fig. 4, it is difficult to give an average aspect ratio for the graphene nanoplatelets, due to the variety of shapes, lengths and thicknesses, the precision of the apparatus, and the relatively small scale of the pictures. To obtain more quantitative information concerning the size and orientation of the nanoplatelets, indirect scattering methods could unfortunately not be performed because the graphene concentrations in the samples are too low for simple scattering characterization.

In consequence we can approximate the aspect ratio assuming the graphene thickness is $2-10 \mathrm{~nm}$ as given by the material provider. Then the aspect ratio $A_{\mathrm{f}}=$ length/thickness, depending on whether one has a wrinkled or flat shape of the nanoplatelet, can be estimated to range from 5 to 10 (wrinkled particles) up to 100-300 (flatter ones). In the next section we compare these values of aspect ratio with estimates from mechanical reinforcement data and the Mori-Tanaka model of composite reinforcement [31].

\subsection{Glass transition temperature}

Polymers are frequently used at ambient temperature or above and this can be a high fraction of the glass transition temperature [32]. Because of this a change in $T_{\mathrm{g}}$ can impact the thermoviscoelastic response of the polymer matrix significantly $[10,32]$. Hence it is important to establish that any observed stiffness increase in a nanocomposite relative to the neat resin is not simply the result of an increased $T_{\mathrm{g}}$. For example, a $16{ }^{\circ} \mathrm{C}$ increase in $T_{\mathrm{g}}$ in poly(ethyl methacrylate) (PEMA) with $0.25 \mathrm{wt} \%$ graphene oxide gives an apparent $25 \%$ reinforcement at room temperature, and this could be mistaken for a large graphene oxide reinforcement [10]. Therefore to quantitatively study the reinforcement of the planar oriented graphene, the glass transition temperatures of samples taken so that they comprised the entire film thickness were studied by DSC and normalized heat capacity was determined to compare $T_{\mathrm{g}}$ variations [33]. As shown in Fig. 5 , the $T_{\mathrm{g}}$ is observed to increase by approximately $1.5-2{ }^{\circ} \mathrm{C}$ upon the addition of $2 \mathrm{wt} \%$ graphene to both the PMMA and PS thin layers. Hence the shift of the $T_{\mathrm{g}}$ due to the presence of graphene in the present work is small, unlike previous work with the nanocomposites of PEMA/graphene oxide. [10] Subsequently, we show that this small change of $T_{\mathrm{g}}$ results in only modest apparent reinforcement and that most of the reinforcement observed in the present work occurs due to the oriented graphene and not to the change in $T_{\mathrm{g}}$ due to confining effects of the nanofillers.

\subsection{Mechanical properties}

From the microscopy we can see that, as we hypothesized, the forced assembly method succeeds in orienting, to some extent, the 

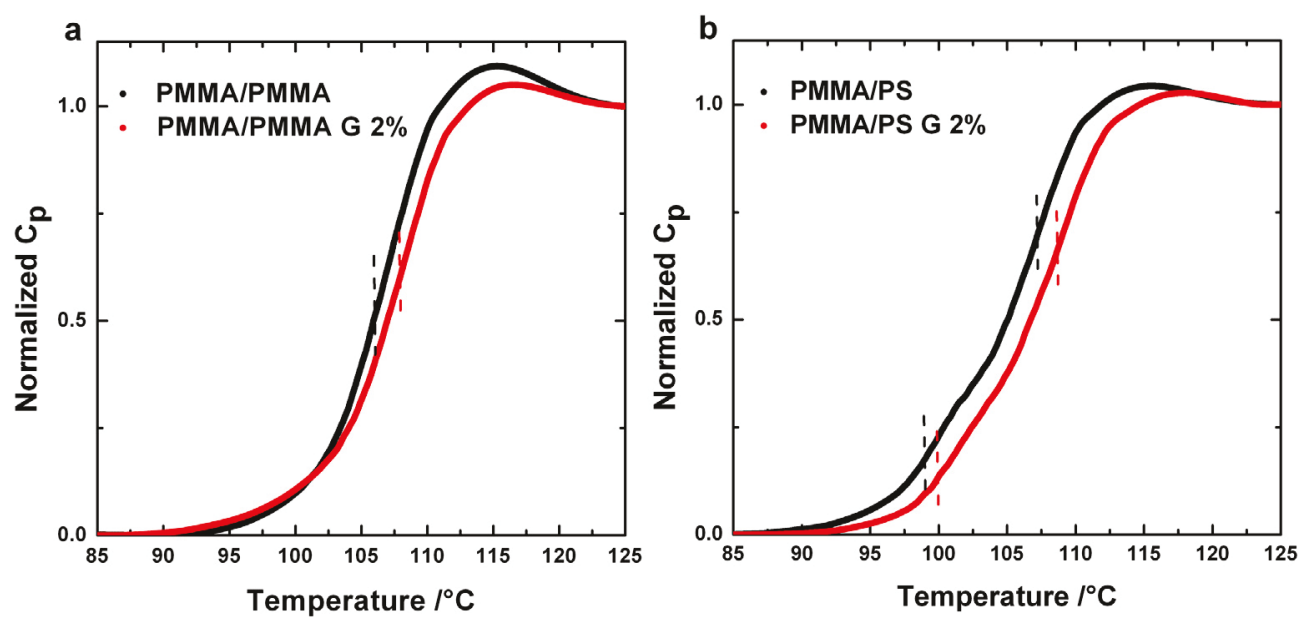

Fig. 5. DSC results for the (a) 2049L PMMA/PMMA-graphene and (b) 2049L PMMA/PS-graphene systems. Reinforcing layers contain 2 wt \% graphene.

graphene in the plane of the layers. Therefore, in the direction of the orientation, nanocomposites with such structures should provide enhanced stiffening of the composites in the plane directions in which the graphene platelets are aligned. To confirm the microscopic observations, we examine the stiffening or reinforcement of the multilayer composites in two ways. We first considered the modulus of the multilayer films, themselves. The results show, in this case, modest reinforcement because the individual reinforcing elements (individual layers filled with graphene) make up only $10 \%$ of the film itself and, so, are effectively diluted. We, therefore, then analyzed the results by estimating properties of the single, graphene-filled, layers. We have also analyzed the experimental results within the framework of the Mori-Tanaka model which gives an additional estimate of the graphene platelet aspect ratio. This was found to be in the same range as the estimates obtained from the microscopy measurements for flattened nanoplatelets.

\subsubsection{Reinforcement of multilayer films}

Fig. $6 a$ and $b$ show the relative stiffening of the multilayer films along extrusion flow direction based on the quasi-static tension tests and dynamic mechanical tests, respectively. The figures show the ratio $E / E_{\mathrm{m}}$ of the composite modulus $E$ to the modulus $E_{\mathrm{m}}$ of the corresponding unfilled multilayer film (for
PMMA/PMMA, $E_{\mathrm{m}}=2.89 \mathrm{GPa}$; for PMMA/PS, $E_{\mathrm{m}}=2.71 \mathrm{GPa}$, as measured in our lab). The results are plotted as a function of the weight fraction of graphene in the full film. From the quasistatic tension tests, we see that as the addition of graphene increases to $0.2 \mathrm{wt} \%$ for the total film, the reinforcement is $11.0 \%$ for the 2049-layer PMMA/PMMA-graphene film ( $E=3.21 \mathrm{GPa})$ and $4.2 \%$ for the 2049-layer PMMA/PS -graphene film $(E=2.82 \mathrm{GPa})$. In addition, as expected, the reinforcement due to the graphene in the 2049-layer film is greater than in 129layer and 3-layer films, consistent with the idea that increasing the number of layers improves the graphene orientation. From Fig. $6 \mathrm{~b}$ we see that the DMA results give a similar trend, but somewhat weaker than the quasi-static tension test, i.e., approximately $8 \%$ increase in modulus for the $0.2 \%$ graphene in PMMA/PMMA system. The slight difference can possibly be explained because the DMA tests were performed at $1.0 \mathrm{~Hz}$ and $40{ }^{\circ} \mathrm{C}$ while the static tension tests were performed at a rather low strain rate of $7.6 \times 10^{-4} / \mathrm{s}$ and at room temperature. In addition, in fracture toughness tests (data not shown), up to $0.2 \mathrm{wt} \%$ graphene, the brittleness of the films does not change significantly.

The PMMA/PS-graphene films made from the commercial master batch appear to display weaker reinforcement than PMMA/ PMMA-graphene made from the lab-made master batches. This
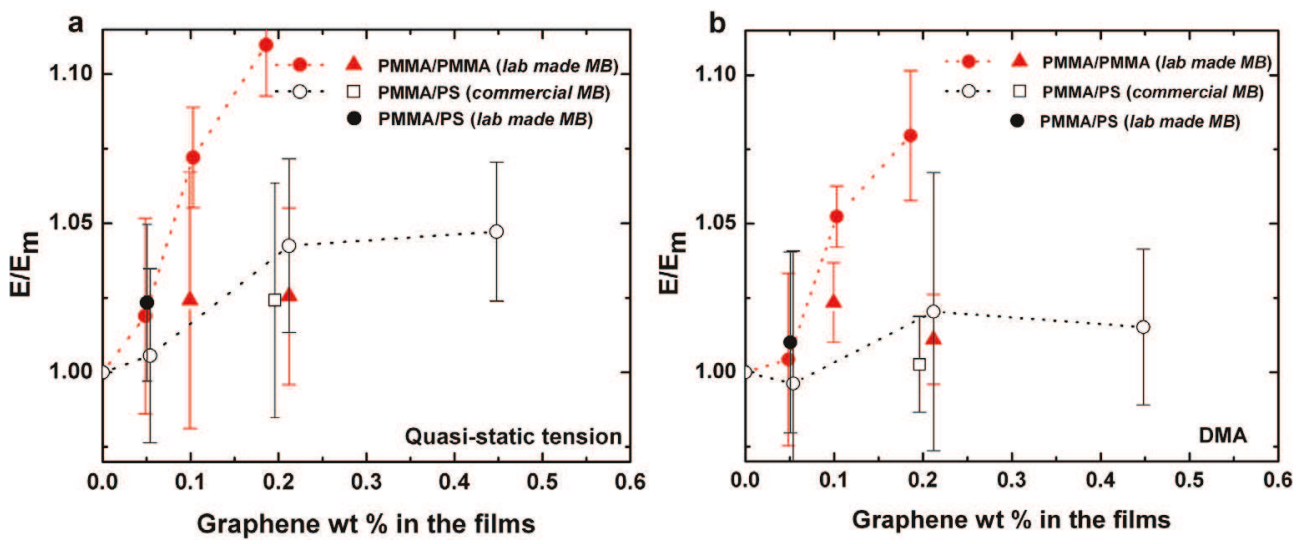

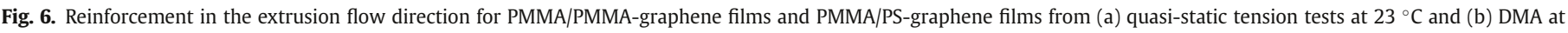
$40{ }^{\circ} \mathrm{C}$. (Circles: 2049-layer; Squares: 129-layer; Triangles: 3-layer.) 
might be due to the poor bonding between graphene and PS or the poor bonding between the PS and PMMA layers. ${ }^{1}$ In addition, we note that the commercially supplied master batch has additives in the mix to improve the graphene dispersion and this could also be a factor in the lower reinforcement. Regardless, in what follows we consider only the PMMA/PMMA-graphene system in an examination of the reinforcement in terms of the individual graphene reinforced layers rather than the total film.

\subsubsection{Reinforcement of a single, graphene filled PMMA layer}

From the measurements on the multilayer films, we can estimate the modulus of the actual single, graphene filled layer (see equation (1)). Although the microscopy was not conclusive that there are distinct filled/unfilled layers in the PMMA/PMMAgraphene system, it is still reasonable to assume, in a first order approximation, that the graphene nanoplatelets are mainly confined within the thin PMMA layers and aligned in the flow direction. Such an assumption is reasonable because of the short residence time of the melt streams and slow diffusion of the graphene nanoplatelets in the mixing elements ( $\sim 2 \mathrm{~min}$ ). Using the Stokes-Einstein equation [35] and an equivalent spherical diameter [36] for the graphene nanoplatelets. For example, for diameters of $28.8 \mathrm{~nm}$ (for a $5 \mathrm{~nm} \times 50 \mathrm{~nm} \times 50 \mathrm{~nm}$ platelet) and $72.6 \mathrm{~nm}$ (for a $5 \mathrm{~nm} \times 200 \mathrm{~nm} \times 200 \mathrm{~nm}$ platelet), the mean-square diffusion displacement in $2 \mathrm{~min}$ is estimated to be $1130 \mathrm{~nm}^{2}$ $(d \approx 34 \mathrm{~nm})$ and $449 \mathrm{~nm}^{2}(d \approx 21 \mathrm{~nm})$, respectively, for a melt viscosity of 5367 Pa.s at a temperature of $225^{\circ} \mathrm{C}$. Considering the concentration of graphene, the system is not a dilute dispersion, and we would, therefore, expect that the particle diffusion should be slower than the Stokes-Einstein estimate because of the particle interactions [37]. Hence, the actual diffusion displacement of the graphene nanoplatelets would be significantly less than the above estimates. In addition, even if there are stacks of graphene, the larger particles should have even slower diffusion than the simple Stokes-Einstein estimates above. To conclude, even not considering that the particles need to move laterally to the (apparent) orientation direction nor the fact that the diameter reductions would be greatest in the last stage of the process, the distance migrated out of the confining layer by the graphene nanoplatelets should not be enormous. The examination of the reinforcement of the single PMMA layer containing the graphene, and the comparison with micromechanical predictions assuming alignment of the nanoplatelets, provides us with insight into the advantages of the forced assembly in orienting the graphene. It also provides information about the efficiency of orientation within the single layers. This is particularly relevant if one can eventually make multilayer systems in which all of the layers are of nanometer thickness and reinforced by graphene.

The tensile modulus $E_{\text {single }}$ of a single graphene filled PMMA layer can be estimated using equation (1), which corresponds to the results from the Voigt upper bound mixing rule [38], where $V_{\text {thick }}$ and $V_{\text {single }}$ are the volume fraction of the unfilled thick PMMA layers and single graphene filled PMMA layers, respectively.

$E_{\text {single }}=\frac{E-V_{\text {thick }} E_{\mathrm{m}}}{V_{\text {single }}}$

In order to obtain further insight into the single layer reinforcement, we used the Mori-Tanaka model [31] to analyze the graphene reinforcement in the single filled PMMA layer. Tandon

\footnotetext{
${ }^{1}$ We note that a significant spontaneous delamination between the PMMA and PS layers occurred after two months of the samples sitting at ambient conditions in the lab, apparently due to the low interfacial adhesion between the immiscible PS and PMMA layers [34]
}

and Weng [39] have derived an analytical form of the Mori-Tanaka model for the tensile modulus in composites with unidirectionally aligned isotropic platelets:

$$
\frac{E}{E_{\mathrm{m}}}=\frac{1}{\left(1+V_{\mathrm{f}}\left(-2 \nu_{\mathrm{m}} A_{3}-\left(1-\nu_{\mathrm{m}} A_{4}+\left(1+\nu_{\mathrm{m}}\right) A_{5} A\right)\right)\right) / 2 A}
$$

where $E_{\mathrm{m}}, \nu_{\mathrm{m}}$, and $V_{\mathrm{f}}$ are tensile modulus of PMMA, Poisson's ratio of PMMA and volume fraction of graphene, respectively. $A$ and $A_{\mathrm{i}}$ are functions of $V_{\mathrm{f}}, \nu_{\mathrm{m}}$ and the Eshelby tensors provided by Tandon and Weng. [39] In the case of the single layer, $E_{\text {single }}=E$. We have assumed $E_{\mathrm{m}}=2.89 \mathrm{GPa}, \nu_{\mathrm{m}}=0.35$. and the tensile modulus of the graphene sheet was taken as $1060 \mathrm{GPa}$ (value measured by nanoindentation [40]). At low volume fraction, the Mori-Tanaka model is insensitive to the Poisson's ratio of the filler and we have assumed that graphene is isotropic with a Poisson's ratio of 0.006. [41]

In Fig. 7, for the case of the $2 \mathrm{wt} \%$ graphene in the individual layer, the degree of apparent reinforcement is $118 \%$ (from the quasistatic tension tests) and $86 \%$ (from the DMA results). These results are close to the predictions from the Mori-Tanaka model with $A_{\mathrm{f}}=225$ or 137 , for quasi-static or DMA testing, respectively. This is similar to values from 100 to 300 estimated from the electron microscopy images described previously for the flattened nanoplatelets. The high amount of reinforcement is significantly greater than previously reported for reinforcements in isotropic or random dispersions of graphene in polymer matrices. For example, a $2 \mathrm{wt} \%$ graphene dispersed in PMMA by in situ polymerization gave a 39\% reinforcement [4] and a 2 wt \% graphene dispersed in polycarbonate by melt mixing gave a $21 \%$ reinforcement [13]. Importantly, the single layer analysis shows that we achieve significant reinforcement in the polymer by orientation induced by forced assembly.

With regard to the small increase in $T_{\mathrm{g}}$, we modified the mechanical results versus temperature to give corrected reinforcement $E\left(T-T_{\mathrm{g}}\right) / E_{\mathrm{m}}\left(T-T_{\mathrm{g}}\right)$ [10], and also compared the results with the Mori-Tanaka model. In that case the fitting parameter $A_{\mathrm{f}}$ gave values of 180 and 102 for quasi-static and DMA experiments respectively, as shown in Fig. 7, again in the range of the estimated $A_{\mathrm{f}}$ values for aligned nanoplatelets, obtained from the electron microscopy images. For the $2 \mathrm{wt} \%$ graphene in the filled layer, the reinforcement is $101 \%$ (from quasi-static tension test) or $69 \%$ (from DMA), still higher than previously reported reinforcements in isotropic or random dispersions. A point worth making here is that comparison of the corrected reinforcement with the apparent reinforcement, shows that there is an extra 15-20\% reinforcement that arises from the relatively small change in $T_{\mathrm{g}}$.

We have also examined the two-dimensional reinforcement in the single layer from the measurements of modulus perpendicular to the extrusion direction. Indeed, when the film leaves the extruder, its thickness is close to $1 \mathrm{~mm}$, whereas the final film thickness obtained after the chill-roll is between 0.3 and $0.5 \mathrm{~mm}$, indicating orientation of the polymer chains. A point of importance here is that annealing of the samples above $T_{\mathrm{g}}$ and watching them de-orient, gives the result that the deorientation is approximately the same for the graphene filled and unfilled system. We interpret this to imply that the addition of the graphene does not significantly change the orientation of polymer chains induced by the multilayer extrusion process. Hence, we can compare the reinforcement relative to the neat resin properties using the extruded film estimates and the neat PMMA/PMMA multilayer film properties of the tensile modulus of $2.89 \mathrm{GPa}$ and $2.08 \mathrm{GPa}$, along flow and transverse directions, respectively. We compare the mechanical properties by considering the tensile modulus of the single graphene filled layer, along both flow and transverse directions. Fig. 8 

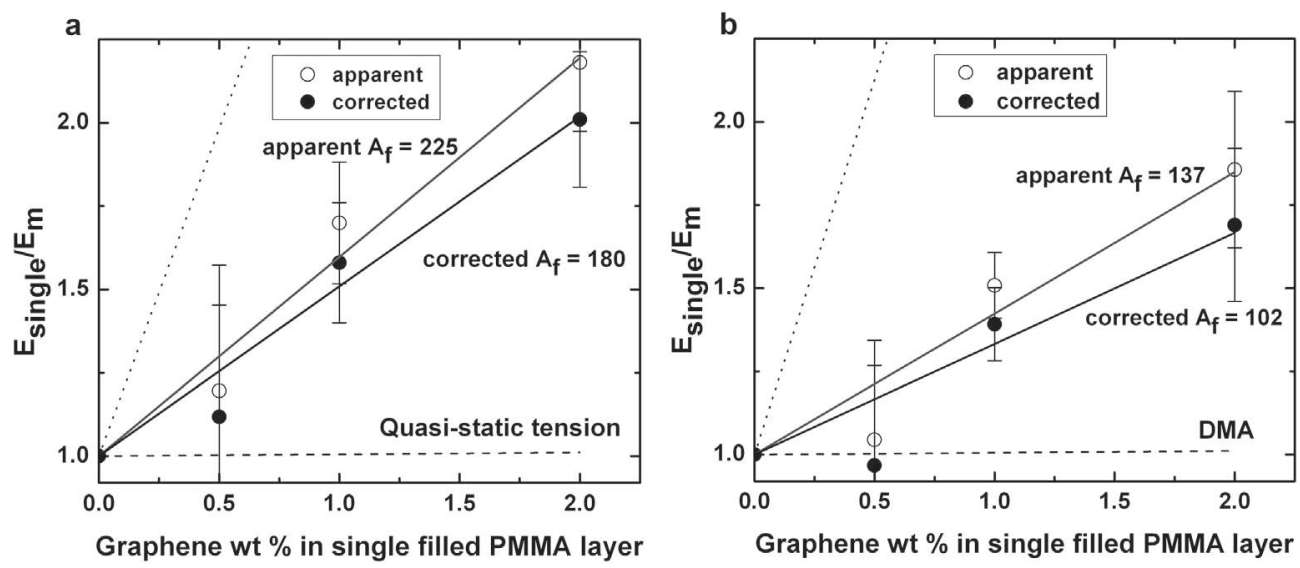

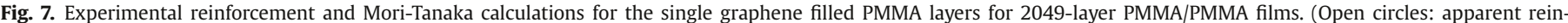

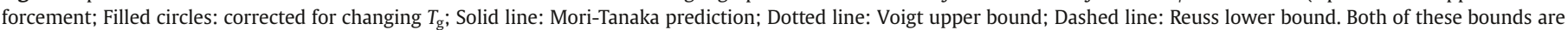
estimated from the moduli of graphene and neat PMMA).

presents the $T_{\mathrm{g}}$ corrected reinforcements of flow and transverse directions. We see from the figure that the transverse reinforcement is weaker than that of the flow direction and the difference between the two gets larger the higher the graphene content. We discuss the possible mechanism in the next section.

\subsubsection{Graphene orientation}

The ability to create a two-dimensional, maybe nacre-like, structure that gives isotropic in-plane stiffening through platelet orientation [42] is a promising advantage of the forced assembly method of making graphene or other platelet-like nanocomposites. In the previous section we saw that we obtained very good reinforcement of the single graphene reinforced layers in the flow direction and more modest reinforcement in the perpendicular direction. To explain our observations of planar reinforcement and its anisotropy (which cannot be explained by the presence of wrinkled, almost isotropic, graphene nanoplatelets) we can apply the Krenchel's approach [43] and Brune and Bicerano's model of "small off-plane deviation: imperfect planar orientation" [44].

There are some studies that explore how platelet-like particles orient during flow [43-46]. Although numerical methods predict that the major axis of rectangular platelet-like particles aligns in the shear flow direction [45], in Paul's work of polymer/nanoclay

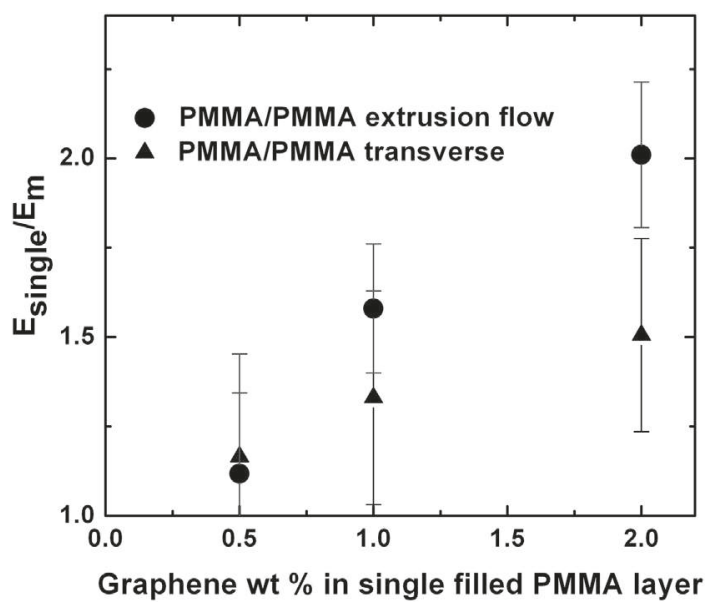

Fig. 8. Comparison of $T_{\mathrm{g}}$ corrected reinforcements between flow and transverse directions for 2049-layer PMMA/PMMA. composites produced by injection molding, a lower degree of alignment of platelets was observed by TEM in the transverse direction compared to the flow direction [46]. Paul also reported higher thermal expansion coefficients in the transverse direction, corresponding to the non-uniform orientation [46]. This work indicated an imperfect planar orientation of platelet-like particles, and there has been some theoretical work to predict the effect of imperfect alignment on the composites properties. Both Lele et al. [43] using Krenchel's approach [47] and Brune and Bicerano [44] using a numerical method, showed that a small off-plane deviation from perfect planar orientation of platelet-like particles can reduce the reinforcement significantly.

When graphene nanoplatelets are in such an imperfect planar orientation or "tilted" in the transverse direction, we can estimate the transverse reinforcement from the axial reinforcement (Brune and Bicerano assumed that the axial reinforcement equals to the maximum reinforcement for perfect planar orientation) as being tilted at an angle $\theta$ to the flow direction with the following method: If we assume that the individual graphene filled PMMA layer thickness is $35 \mathrm{~nm}$ and the length of the graphene nanoplatelets confined in the layer is $120 \mathrm{~nm}$, the maximum tilted angle $\theta$ equals to $\sin ^{-1}(35 / 120)=17^{\circ}$. Following Krenchel's approach $[43,47]$, we can estimate the lateral tensile modulus using equation (3):

$E=E_{\mathrm{m}} V_{\mathrm{m}}+\cos ^{4} \theta E_{\mathrm{f}} V_{\mathrm{f}}$

where $\theta$ is the tilted angle to the flow direction, equaling to the angle to the lateral tensile load direction $E_{\mathrm{f}}$ is the tensile modulus of the graphene sheet. Krenchel's approach (equation (3)) gives a value of the transverse reinforcement $\left(E / E_{\mathrm{m}}\right)$ transverse $=0.86(E)$ $\left.E_{\mathrm{m}}\right)_{\text {axial }}$, which is somewhat higher than the experimental results presented in Fig. 8. Brune and Bicerano [44] solved the full tensor constitutive equations numerically and, from their graphical solution we estimate that $\left(E / E_{\mathrm{m}}\right)_{\text {transverse }}=0.75\left(E / E_{\mathrm{m}}\right)_{\text {axial, }}$ closer to the experimental result. Future work should explore the possibility that this imperfect planar orientation could be improved by combining the multilayer coextrusion with an external biaxial stretch [20].

\section{Conclusions}

We have used forced assembly through multilayer extrusion methods to create PMMA/PS-graphene and PMMA/PMMAgraphene multilayer films. A combination of microscopic analysis 
of the morphology of the multilayer films and mechanical property measurements provides evidence that the reinforced layers contain oriented graphene in the direction of extrusion and partially oriented in the transverse direction. The amount of reinforcement is greater than normally reported for graphene nanocomposites and has been attributed primarily to the graphene orientation and not to the small increase in the glass transition temperature of the reinforced matrix. For the PMMA/PMMA-graphene system with $2 \%$ by weight loading of graphene in the thinnest layers ( $35 \mathrm{~nm}$ ), the room temperature, flow direction tensile modulus is 2.18 times that of the neat resin while accounting for the increased $T_{\mathrm{g}}$ reduces the estimated reinforcement to approximately 2.01 times that of the neat polymer matrix, still a significant effect. For the $40{ }^{\circ} \mathrm{C}$ data from dynamic testing the similar relative moduli are 1.86 and 1.69 for the non $\mathrm{T}_{\mathrm{g}}$-adjusted and $\mathrm{T}_{\mathrm{g}}$-adjusted values, respectively. The lateral degree of reinforcement at the same graphene loading in the PMMA/ PMMA-graphene system is approximately $75 \%$ that of the flow direction reinforcement, leaving room for improvement in the properties in the transverse direction. The results suggest that forced assembly by multilayer extrusion offers the opportunity of creating layered structures with high degrees of in-plane reinforcement and further refinements of the method should be developed.

While some of the results for the PMMA/PS-graphene are similar to those of the PMMA/PMMA-graphene system, the material is not very strong and weakens with time, possibly due to poor adhesion between the PS and the graphene and the weak interface between PMMA and PS. It has been suggested that the interface can be improved by the use of block copolymer compatibilizers to prevent delamination in this system $[34,48]$.

\section{Acknowledgements}

X.Li thanks both the Embassy of France in the United States for a Chateaubriand fellowship and PIMM laboratory at Arts et Métiers ParisTech for the financial support during the work in Paris, France. The PIMM lab HITACHI 4800 SEM has been funded with the help of the SESAME program of Île-de-France Region, Arts et Métiers ParisTech and CNRS. The John R. Bradford Endowment at Texas Tech University is also thanked for partial financial support. The authors also thank A. Grandmontagne for her help in fabricating the multilayer films, and $F$. Valès for his help with the electron microscopy.

\section{References}

[1] Geim K, Novoselov KS. Nat Mater 2007:183.

[2] Kim H, Abdala AA, Macosko CW. Macromolecules 2010;43:6515-30.

[3] Ramanathan T, Abdala AA, Stankovich S, Dikin DA, Herrera-Alonso M Piner RD, et al. Nat Nanotechnol 2008;3:327-31.
[4] Potts JR, Lee SH, Alam TM, An J, Stoller MD, Piner RD, et al. Carbon 2011;49: 2615-23.

[5] Wang H, Casalongue HS, Liang Y, Dai H. J Am Chem Soc 2010;132:7472-7.

[6] Zhang X, Hikal WM, Zhang Y, Bhattacharia SK, Li L, Panditrao S, et al. Appl Phys Lett 2013;102:141905.

[7] Potts JR, Murali S, Zhu Y, Zhao X, Ruoff RS. Macromolecules 2011;44:6488-95.

[8] Padawer GE, Beecher N. Polym Eng Sci 1970;10:185-92.

[9] Jackson AP, Vincent JFV, Turner RM. Compos Sci Technol 1989;36:255-66.

[10] Li X, McKenna GB. ACS Macro Lett 2012;1:388.

[11] Carotenuto G, Nicola SD, Palombal M, Pullini D, Horsewell A, Hansen TW, et al. Nanotechnology 2012;23:485705.

[12] Wu H, Rook B, Drzal LT. Polym Compos 2013;34:426-32.

[13] Kim H, Macosko CW. Polymer 2009;50:3797-809.

[14] Bian J, Wei X, Lin H, Chang T, Sancaktar E. J Appl Polym Sci 2013;128:600-10.

[15] Lepoittevin B, Pantoustier N, Devalckenaere M, Alexandre M, Calberg C, Jerome R. Polymer 2003;44:2033.

[16] Potschke P, Bhattacharyya AR, Janke A. Carbon 2004;42:965.

[17] Liu RYF, Bernal-Lara TE, Hiltner A, Baer E. Macromolecules 2005;38:4819-27.

[18] Ponting M, Hiltner A, Baer E. Macromol Symp 2010;294-I:19-32.

[19] Wang H, Keum JK, Hiltner A, Baer E, Freeman B, Rozanski A, et al. Science 2009;323:757-60.

[20] Gupta M, Lin Y, Deans T, Baer E, Hiltner A, Schiraldi DA. Macromolecules 2010:43:4230-9.

[21] Liu RYF, Jin Y, Hiltner A, Baer E. Macromol Rapid Commun 2003;24:943-8.

[22] Ivan'kova EM, Krumova M, Michler GH, Koets PP. Colloid Polym Sci 2004;282: 203-8.

[23] Sekelik DJ, Stepanov EV, Nazarenko S, Schiraldi D, Hiltner A, Baer E. J Polym Sci B Polym Phys 1999;37:847-57.

[24] Wen M, Sun X, Su L, Shen J, Li J, Guo S. Polymer 2012;53:1602-10.

[25] Miquelard-Garnier G, Guinault A, Fromonteil D, Delalande S, Sollogoub C. Polymer 2013;54:4290-7.

[26] Ania F, Baltá-Calleja FJ, Henning S, Khariwal D, Hiltner A, Baer E. Polymer 2010;51:1805-11.

[27] Alig I, Pötschke P, Lellinger D, Skipa T, Pegel S, Kasaliwal GR, et al. Polymer 2012;53:4-28.

[28] Moynihan CT, Easteal AJ, DeBolt MA, Tucker J. J Am Ceram Soc 1976;59:12.

[29] Badrinarayanan P, Zheng W, Li Q Simon SL. J Non-Cryst Solids 2007;353: 2603-12.

[30] Pedro Aguilera I, Gómez C. Patent EP2548657 A1; 2011.

[31] Mori T, Tanaka K. Acta Metall 1973;21:571-4.

[32] McKenna GB. Dynamics of materials at the nano-scale. In: Utracki LA, Jamieson AM, editors. Polymer physics: from suspensions to nanocomposites and beyond. New York: Wiley; 2010. p. 191-223. Chapter5.

[33] Koh YP, Simon SL. J Polym Sci Part B Polym Phys 2008;46:2741-53.

[34] Zhang J, Lodge TP, Macosko CW. J Rheol 2006;50:41-57.

[35] Einstein A, Furth R, Cowper AD. Investigations on the theory of the Brownian movement. Mineola, NY: Courier Dover Publications; 1956.

[36] Floquet S, Brun S, Lemonnier J, Henry M, Delsuc M, Prigent Y, et al. J Am Chem Soc 2009;131:17254-9.

[37] Banchio AJ, Nägele G, Bergeholtz J. J Chem Phys 1999;111:8721-40.

[38] Liu B, Feng X, Zhang S. Compos Sci Technol 2009;69:2198-204.

[39] Tandon GP, Weng GJ. Polym Compos 1984;5:327-40.

[40] Lee C, Wei X, Kysar JW, Hone J. Science 2008;321:385-8.

[41] Cho J, Luo JJ, Daniel IM. Compos Sci Technol 2007;67:2399.

[42] Paul DR, Robeson LM. Polymer 2008;49:3187-204.

[43] Galgalia G, Agarwal S, Lele A. Polymer 2004;45:6059-69.

[44] Brune DA, Bicerano J. Polymer 2002;43:369-87.

[45] Yamamoto S, Matsuoka T. J Chem Phys 1997:107:3300-8.

[46] Yoon PJ, Fornes TD, Paul DR. Polymer 2002;43:6727-41.

[47] Krenchel H. Fibre reinforcement. Copenhagen: Akademisk Forlag; 1964.

[48] Zhang J, Lodge TP, Macosko CW. Macromolecules 2005;38:6586-91. 